Research Article

\title{
Robust Control for a Two DOF Robot Manipulator
}

\author{
Fatma Massaoudi (D), Dorsaf Elleuch, and Tarak Damak \\ University of Sfax, Ecole Nationale d'Ingénieurs de Sfax, \\ Laboratoire des Sciences et Techniques de L'automatique et de L'informatique Industrielle, LR11ES50, 3038 Sfax, Tunisia
}

Correspondence should be addressed to Fatma Massaoudi; fatoum.ing@gmail.com

Received 17 August 2018; Revised 11 February 2019; Accepted 24 March 2019; Published 17 April 2019

Academic Editor: Ephraim Suhir

Copyright ( 2019 Fatma Massaoudi et al. This is an open access article distributed under the Creative Commons Attribution License, which permits unrestricted use, distribution, and reproduction in any medium, provided the original work is properly cited.

In this paper, we present robust control techniques applied on a manipulator robot system: modified sliding mode control (MSMC) and backstepping control (BSC). The purpose is to evaluate SMC and BSC performances, taking into account the model uncertainties. Then, the obtained results of MSMC technique are compared with those of the adaptive sliding mode. Both methods have comparable simulation results which show a good quality of robustness. However, simulation results prove that the modified SMC is more robust, mostly under the effect of external variations and uncertainties.

\section{Introduction}

Different control methodologies and approaches have been used for nonlinear systems (NLSs). Control architectures depend on the system model or structure. These controllers aim to guarantee system robustness, fast convergence, and stability. They can solve many problems such as external disturbance invariance to system uncertainties [1].

In the literature, many controllers have been developed for NLS such as backstepping control [2] and linearizing feedback [3], robust control, adaptive control, and sliding mode technique $[4,5]$. This theory was proposed by Emelyanov in 1950 and has been widespread thanks to its high performance and its ability to solve the problem of stability and robustness $[1,6]$. SMC is one of the powerful methods to control uncertain nonlinear systems as robot manipulators. In [7-9], authors have proved that modified SMC is robust than tracking control. Yet, many researchers have faced some problems like "chattering" which is a high-frequency oscillation of the input and can lead to the saturation and destruction of actuators [10].

Hence, in order to solve this problem, many researchers used boundary layer saturation method, estimated uncertainties strategy $[1,11]$ and high-order sliding mode control [12]. Others have combined sliding mode with another control technique such as adaptive control [13] or backstepping control for NLS such as robotic manipulators [14], in order to reach high performance and ameliorate robustness.

Backstepping approach presents a systematic method for designing a control structure to track a reference signal, by selecting an appropriate Lyapunov function [15].

It is applied to the globally stable and asymptotically adaptive tracking control of a strict feedback nonlinear system.

Backstepping control offers many advantages over the conventional approaches like improving the system performance [16]. It is also known by its robustness and effectiveness [17].

This technique has been very efficiently applied thanks to its systematic and recursive design methodology for nonlinear feedback control [18]. Unlike the feedback linearization method problems such as the precise model requirement, the backstepping approach offers a choice of design tools for nonlinearities accommodation. Moreover, backstepping is known by its flexibility, thanks to its use of recursive Lyapunov functions. For this, the final designed control law can guarantee the stability of the total control system. In aviation technology, the backstepping technique has been used to solve the stabilization and trajectory tracking problems of quadrotor UAVs $[19,20]$. Yet, it is not easy to get satisfactory performance because the controller parameters obtained by the backstepping method are 
arbitrarily chosen. It is necessary to select proper parameters to obtain a good response. In fact, an improper selection of these parameters leads to inappropriate responses or may even lead to the instability of the system.

Many researchers have studied adaptive sliding backstepping control of semistrict feedback systems like Koshkouei and Zinober [21].

In this work, we present a modified SM approach for robust manipulators developed in [4]. We also propose a backstepping controller and we compare the results of both control types.

This paper is organized as follows. In Section 2, we present the system modeling. In Section 3, sliding mode method is developed; then backstepping control is developed in Section 4. Section 5 is devoted to present all results of sliding mode simulation and backstepping simulation followed by a comparative study. Finally, Section 6 contains conclusions.

\section{System Modeling}

In this paper, a two-degree-of-freedom manipulator DOF is considered (Figure 1) [1, 4].

The two DOF manipulator dynamic model can be given as follows $[1,4]$ :

$$
\begin{aligned}
{\left[\begin{array}{l}
\tau_{1} \\
\tau_{2}
\end{array}\right]=} & {\left[\begin{array}{ll}
M_{11} & M_{12} \\
M_{21} & M_{22}
\end{array}\right]\left[\begin{array}{l}
\ddot{q}_{1} \\
\ddot{q}_{2}
\end{array}\right]+\left[\begin{array}{cc}
-c q_{2} & -c\left(\dot{q}_{1}+\dot{q}_{2}\right) \\
c \dot{q}_{1} & 0
\end{array}\right]\left[\begin{array}{l}
\dot{q}_{1} \\
\dot{q}_{2}
\end{array}\right] } \\
& +\left[\begin{array}{cc}
F c_{1} & 0 \\
0 & F c_{2}
\end{array}\right]\left[\begin{array}{l}
\operatorname{sgn}\left(\dot{q}_{1}\right) \\
\operatorname{sgn}\left(\dot{q}_{2}\right)
\end{array}\right]+\left[\begin{array}{cc}
v_{1} & 0 \\
0 & v_{2}
\end{array}\right]\left[\begin{array}{l}
\dot{q}_{1} \\
\dot{q}_{2}
\end{array}\right]+\left[\begin{array}{l}
d_{1} \\
d_{2}
\end{array}\right],
\end{aligned}
$$

where $q=\left[q_{1}, q_{2}\right]^{T}$ : the joints position vector; $\dot{q}=\left[\dot{q}_{1}, \dot{q}_{2}\right]^{T}$ : the joints velocity vector; $\ddot{q}=\left[\ddot{q}_{1}, \ddot{q}_{2}\right]^{T}$ : the joints acceleration vector; $d=\left[d_{1}, d_{2}\right]^{T}$ : the joints external disturbance vector; $u=\left[\tau_{1}, \tau_{2}\right]^{T}$ : the joints control vector; $F c_{i}$ : the Coulomb friction forces; $v_{i}$ : the viscose friction coefficients. $M_{11}=a_{1}+2 a_{3} \cos \left(q_{2}\right)-2 a_{4} \sin \left(q_{2}\right), M_{12}=M_{21}=$ $a_{2}+a_{3} \cos \left(q_{2}\right)-a_{4} \sin \left(q_{2}\right)$, and $M_{22}=a_{2}$, where $c=a_{3}$ $\sin \left(q_{2}\right)+a_{4} \cos \left(q_{2}\right), a_{1}=l_{1}+m_{1} l_{c 1}^{2}+I_{e}+m_{e} l_{c e}^{2}+m_{e} I_{1}^{2}, a_{2}=$ $I_{e}+m_{e} l_{c e}^{2}, a_{3}=\cos (30) m_{e} l_{c e} l_{1}$, and $a_{4}=\sin (30) m_{e} l_{c e} l_{1}$.

The system equation (1) can be written as follows:

$$
\ddot{q}=M^{-1}\left(u-C(\dot{q})-F c_{i} \operatorname{sgn}(\dot{q})-v_{i}(\dot{q})-d\right),
$$

where $f(q, \dot{q})=M^{-1}\left(-C(\dot{q})-F c_{i} \operatorname{sgn}(\dot{q})-v_{i}(\dot{q})\right)$.

Then, the second form of the dynamic model has the following expression:

$$
\ddot{q}=B(q) u+f(q, \dot{q}),
$$

where $q=\left[q_{1}, q_{2}\right]^{T}, u=\left[\tau_{1}, \tau_{2}\right]^{T}, B(q)=M^{-1}$.

In the presence of uncertainties, functions $f(q, \dot{q})$ and $B(q)$ have the following form [4]:

$$
\begin{aligned}
f(q, \dot{q}) & =\widehat{f}(q, \dot{q})+\Delta f(q, \dot{q}), \\
B(q) & =\widehat{B}(q)+\Delta B(q),
\end{aligned}
$$

where $\Delta f$ and $\Delta B$ are the unknown-parts of $f$ and $B$, respectively, and $f$ and $\widehat{B}$ are the known parts.

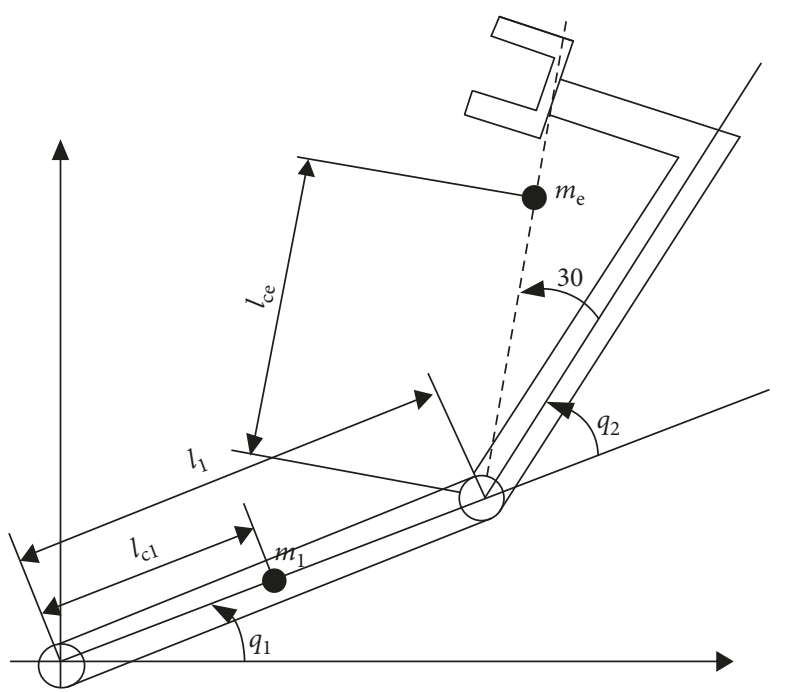

FIgUre 1: A two DOF serial robot manipulator.

\section{Sliding Mode Controller}

3.1. Definition. Sliding mode control depends on the choice of SM surface and how to guarantee the stability and convergence using Lyapunov function. Then, a suitable sliding mode control law is proposed.

Under the sliding conditions $S(x) \dot{S}(x)<0$, the sliding surface should verify $S(x)=0$ and $\dot{S}(x)=0$.

Sliding mode controllers are robust and rapid. But, classical SMC has some disadvantages, especially the chattering phenomenon, which can lead to some troubles such as the heat and saturation of the robotic mechanical parts $[1,6]$.

As a remedy to this problem, many solutions can be used like boundary layer technique, combination of other types of control with sliding mode and higher-order sliding mode $[1,12]$.

An adaptive SMC is used for the two DOF manipulator in [4].

The sliding surface function is chosen as follows $[1,4]$ :

$$
S(t)=\left(\frac{d}{d t}+\Lambda\right)^{2}\left(\int e d t\right)=\dot{e}+2 \Lambda e+\Lambda^{2} \int e d t,
$$

where $\Lambda$ is an $n \times n$ diagonal definite positive constant matrix and $e$ is the vector of tracking error, $e=q-q_{\mathrm{d}}$.

The error rate vector is $\dot{e}=\dot{q}-\dot{q}_{\mathrm{d}}$.

In [4], the authors use an adaptive sliding mode control in which the SMC law is given by the following expression:

$$
u(t)=\widehat{B}^{-1}\left(\ddot{q}_{r}-\widehat{f}-K S-\Gamma \int S d t\right),
$$

where $\Gamma$ is the diagonal definite constant positive matrix and $\ddot{q}_{\mathrm{r}}$ is the reference acceleration. $K, \widehat{B}^{-1}$, and $\widehat{f}$ are defined in [4].

Consider $u_{\mathrm{eq}}=\widehat{B}^{-1}\left(\ddot{q}_{\mathrm{r}}-\hat{f}\right) ; u_{1}=-\widehat{B}^{-1} K S$ and $\hat{u}_{2}=$ $-\widehat{B}^{-1} \Gamma \int S d t$.

So,

$$
u(t)=u_{\mathrm{eq}}+u_{1}+\widehat{u}_{2},
$$


where $\widehat{u}_{2}$ is an adaptive term used to compensate system uncertainties.

In this paper, $\hat{u}_{2}$ is replaced by another term according to sliding technique.

$$
\widehat{u}_{2}=-\widehat{B}^{-1} K \eta \operatorname{sat}(S) .
$$

So, the modified SMC expression is given by

$$
u(t)=\widehat{B}^{-1}\left(\ddot{q}_{\mathrm{r}}-\bar{f}-K(S+\eta \operatorname{sat}(S))\right) .
$$

The SMC block diagram is shown in Figure 2 [4].

$$
R=\eta \operatorname{sat}(S) \text {. }
$$

3.2. Stability Analyzes. The Lyapunov function has the following expression:

$$
v=\frac{1}{2} S^{T} S .
$$

The derivative of Lyapunov function is $\dot{v}=S^{T} \dot{S}$ and $\dot{S}=\ddot{q}-\ddot{q}_{\mathrm{r}}$.

The SMC law is described by

$$
u(t)=\widehat{B}^{-1}\left(\ddot{q}_{\mathrm{r}}-\hat{f}-K(S+\eta \operatorname{sat}(S))\right) .
$$

Since $\ddot{q}=\widehat{B}(q) u+\hat{f}(q, \dot{q}), \quad \dot{v}=S^{T}\left(\ddot{q}-\ddot{q}_{\mathrm{r}}\right)=S^{T}(\widehat{B}(q)$ $\left.\left(\widehat{B}^{-1}\left(\ddot{q}_{\mathrm{r}}-\hat{f}-K(S+\eta \operatorname{sat}(S))\right)\right)+\widehat{f}-\ddot{q}_{\mathrm{r}}\right)$.

Then $\dot{v}=-S^{T} K(S+\eta \operatorname{sat}(S))$.

The stability is proved when $\dot{v} \leq 0$. So, $\eta \geq-(S /$ sat $(S))$.

\section{Backstepping Controller}

4.1. Definition. The backstepping control scheme is a nonlinear control method based on the Lyapunov theorem control. It is a systematic design technique applied to strict feedback systems. BSC has a systematic way of constructing the Lyapunov function along the control input design.

This strategy is used especially in robotic field and it is based on the following points:

(i) Defining the error variable

(ii) Defining Lyapunov function

(iii) Derivating Lyapunov function

(iv) Determining a virtual variable

(v) Defining the next integrator until the apparition of the real control variables

The most important object of backstepping control is to make loop systems equivalent to one-order system that verifies the Lyapunov stability.

4.2. Stability Analyzes. Consider the following state vector:

$$
x_{i}=\left[x_{1}, x_{2}, x_{3}, x_{4}\right]^{T}=\left[q_{1}, \dot{q}_{1}, q_{2}, \dot{q}_{2}\right] .
$$

Then, the system model is subdivided into two subsystems. The first subsystem is described by

$$
\begin{aligned}
\dot{x}_{1}= & x_{2}, \\
\dot{x}_{2}= & \frac{\tau_{1}}{M_{11}}-\frac{M_{12}}{M_{11}} \dot{x}_{4}+2 c \frac{x_{2} x_{4}}{M_{11}}+\frac{c}{M_{11}} x_{4}^{2}-\frac{F c_{1}}{M_{11}} \operatorname{sgn}\left(x_{2}\right) \\
& -\frac{v_{1}}{M_{11}} x_{2}-\frac{d_{1}}{M_{11}} .
\end{aligned}
$$

And the second subsystem is described by

$\dot{x}_{3}=x_{4}$,

$\dot{x}_{4}=\frac{\tau_{2}}{M_{22}}-\frac{M_{21}}{M_{22}} \dot{x}_{2}-c \frac{x_{2}^{2}}{M_{22}}-\frac{F c_{2}}{M_{22}} \operatorname{sgn}\left(x_{4}\right)-\frac{v_{2}}{M_{22}} x_{4}-\frac{d_{2}}{M_{22}}$.

The error variable is given as

$$
z_{i}=x_{i}-x_{i d}
$$

$i=1, \ldots, n$, where $n=2$ and $x_{i d}$ is the desired state vector.

The derivative of $z_{i}$ is

$$
\begin{aligned}
& \dot{z}_{i}=\dot{x}_{i}-\dot{x}_{i d}, \\
& \dot{z}_{i}=\dot{x}_{i}-\dot{x}_{i d} .
\end{aligned}
$$

The Lyapunov function can be written as

$$
v_{i}=\frac{1}{2} z_{i}^{2}
$$

Then its derivative is

$$
\begin{aligned}
& \dot{v}_{i}=z_{i} \dot{z}_{i}, \\
& \dot{v}_{i}=-c_{i} z_{i}^{2}+z_{i}\left(c_{i} z_{i}+x_{i+1}-\dot{x}_{i d}\right),
\end{aligned}
$$

where $c_{i}$ are the backstepping variables.

In order to guarantee the system stability, the following condition should be verified:

$$
\begin{array}{ll} 
& \dot{v}_{i} \leq 0, \\
\text { the virtual control } \quad \alpha_{i}=-c_{i} z_{i}=-c_{i}\left(x_{i}-x_{i d}\right) .
\end{array}
$$

The Lyapunov function can be written as

$$
v_{i+1}=\frac{1}{2} z_{i+1}^{2}+v_{i}
$$

The stability is proved when

$$
\dot{v}_{i+1} \leq 0 \text {. }
$$

4.2.1. For the First Subsystem. The first error variable is $z_{1}=$ $x_{1}-x_{1 d}$ and its derivative is $\dot{z}_{1}=\dot{x}_{1}-\dot{x}_{1 d}=x_{2}-\dot{x}_{1 d}$.

The first Lyapunov function is $v_{1}=(1 / 2) z_{1}^{2}$ and its derivative is $\dot{v}_{1}=z_{1} \dot{z}_{1}$. So, $\dot{v}_{1}=-c_{1} z_{1}^{2}+z_{1}\left(c_{1} z_{1}+x_{2}-\dot{x}_{1 d}\right)$.

The virtual control is

$$
\alpha_{1}=-c_{1} z_{1}=-c_{1}\left(x_{1}-x_{1 d}\right) .
$$

The first error variable is $z_{2}=c_{1} z_{1}+x_{2}-\dot{x}_{1 d}, z_{2}=-\alpha_{1}+$ $x_{2}-\dot{x}_{1 d}$ and its derivative is $\dot{z}_{2}=c_{1} \dot{z}_{1}+\dot{x}_{2}-\ddot{x}_{1 d}, \dot{z}_{2}=$ $c_{1}\left(\dot{x}_{1}-\dot{x}_{1 d}\right)+\dot{x}_{2}-\ddot{x}_{1 d}$. 


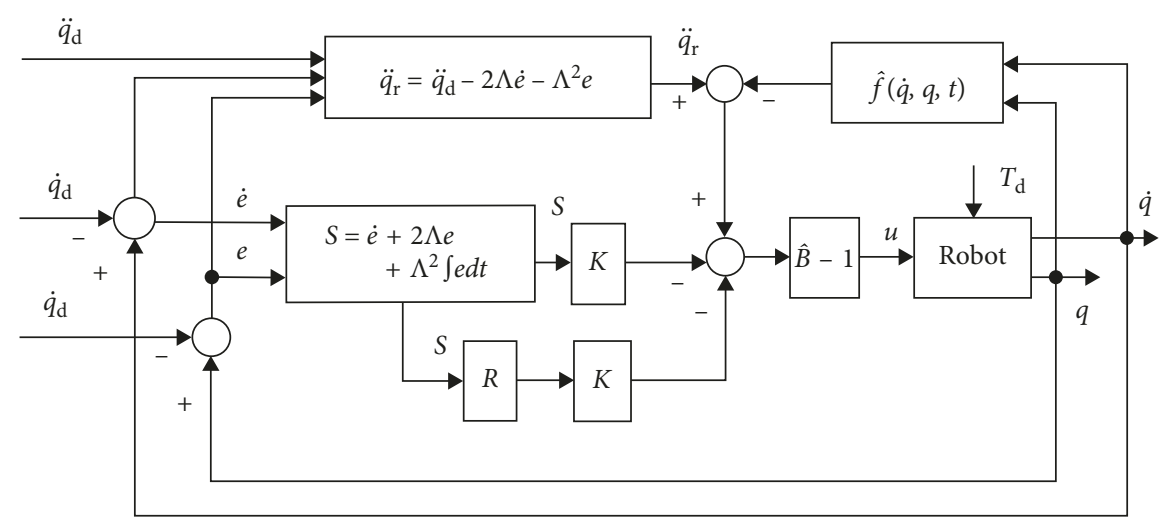

Figure 2: SMC block diagram [4].

Since $\dot{x}_{2}=f_{1}+g_{1} \tau_{1}$, with $f_{1}=-\left(M_{12} / M_{11}\right) \dot{x}_{4}+2 c\left(x_{2}\right.$ $\left.x_{4} / M_{11}\right)+\left(c / M_{11}\right) x_{4}^{2}-\left(F c_{1} / M_{11}\right) \operatorname{sgn}\left(x_{2}\right)-\left(v_{1} / M_{11}\right) x_{2}-\left(d_{1}\right.$ $\left./ M_{11}\right)$ and $g_{1}=1 / M_{11}$.

Then, $\dot{z}_{2}=f_{1}+g_{1} \tau_{1}-\ddot{x}_{1 d}+c_{1}\left(z_{2}+\alpha_{1}\right)$.

The second Lyapunov function is $v_{2}=(1 / 2) z_{2}^{2}+v_{1}$ and its derivative is $\dot{v}_{2}=z_{2} \dot{z}_{2}+\dot{v}_{1}$.

The system stability can be obtained when $\dot{v}_{2} \leq 0, \dot{v}_{2}=$ $-c_{1} z_{1}^{2}+z_{1} z_{2}+z_{2}\left(-c_{2} z_{2}-z_{1}\right), \dot{v}_{2} \leq-c_{1} z_{1}^{2}+z_{1} z_{2}+z_{2}\left(z_{1}-z_{1}+\right.$ $\left.c_{2} z_{2}-c_{2} z_{2}+g_{1} \tau_{1}+f_{1}-\ddot{x}_{1 d}+c_{1} z_{2}+c_{1} \alpha_{1}\right), z_{1}+c_{2} z_{2}+g_{1} \tau_{1}+$ $f_{1}-\ddot{x}_{1 d}+c_{1} z_{2}+c_{1} \alpha_{1}=0$.

Then, $\tau_{1}=\left(1 / g_{1}\right)\left(\ddot{x}_{1 d}-c_{1} x_{2}+c_{1} \dot{x}_{1 d}-f_{1}-x_{1}+x_{1 d}-\right.$ $\left.c_{2} x_{2}+c_{2} \dot{x}_{1 d}-c_{1} c_{2} x_{1}+c_{1} c_{2} x_{1 d}\right)$.

Thus, the expression of the first subsystem BSC law is

$$
\begin{aligned}
\tau_{1}= & M_{11}\left(\ddot{x}_{1 d}-c_{1} x_{2}+c_{1} \dot{x}_{1 d}+\frac{M_{12}}{M_{11}} \dot{x}_{4}-\frac{2 c}{M_{11}} x_{2} x_{4}\right. \\
& -\frac{c}{M_{11}} x_{4}^{2}+\frac{F c_{1}}{M_{11}} \operatorname{sgn}\left(x_{2}\right)+\frac{v_{1}}{M_{11}} x_{2}+\frac{d_{1}}{M_{11}}-x_{1}+x_{1 d} \\
& \left.-c_{2} x_{2}+c_{2} \dot{x}_{1 d}-c_{1} c_{2} x_{1}+c_{1} c_{2} x_{1 d}\right) .
\end{aligned}
$$

4.2.2. For the Second Subsystem. The same steps used for the first subsystem are followed to obtain the expression of the second subsystem BSC which is given by

$$
\begin{aligned}
\tau_{2}= & M_{22}\left(\ddot{x}_{2 d}-c_{3} x_{4}+c_{3} \dot{x}_{2 d}+\frac{M_{21}}{M_{22}} \dot{x}_{2}+\frac{c}{M_{22}} x_{2}^{2}\right. \\
& +\frac{F c_{2}}{M_{22}} \operatorname{sgn}\left(x_{4}\right)+\frac{v_{2}}{M_{22}} x_{4}+\frac{d_{2}}{M_{22}}-x_{3}+x_{2 d}-c_{4} x_{4} \\
& \left.+c_{4} \dot{x}_{2 d}-c_{3} c_{4} x_{3}+c_{3} c_{4} x_{2 d}\right) .
\end{aligned}
$$

\section{Simulation Results}

In this section, tracking results of SMC and backstepping control are shown.
The desired position vectors are chosen as follows [4]:

$$
\begin{aligned}
& q_{d 1}=\frac{\pi}{6}(1-\cos (1.5 \pi t)+\sin (\pi t)), \\
& q_{d 2}=\frac{\pi}{6}(1-\cos (2 \pi t)+\sin (1.5 \pi t)) .
\end{aligned}
$$

In order to reduce the chattering phenomenon, in equation (14), "sign" is replaced by saturation function "sat," where

$$
\begin{aligned}
& \operatorname{sat}(S)=\operatorname{sign}(S), \quad \text { if }|S| \geq \phi, \\
& \operatorname{sat}(S)=\frac{S}{\phi}, \quad \text { otherwise. }
\end{aligned}
$$

The design parameters of simulation are $\eta=1$, $K=1000$, and $\phi=0.8$.

The BSC parameters are chosen as follows:

$$
\begin{aligned}
& c_{1}=30, \\
& c_{2}=40, \\
& c_{3}=80, \\
& c_{4}=300 .
\end{aligned}
$$

The end-effect or mass is $m_{\mathrm{e}}=2 \mathrm{~kg}$.

5.1. Results with the External Perturbation. The external perturbations are applied at $t=3 \mathrm{~s}, d_{1}=200$, and $d_{2}=400$.

Figure 3 represents the tracking manipulator trajectory of joints $\mathrm{J1}$ and $\mathrm{J} 2$, respectively, by sliding mode controller and backstepping controller.

The simulation results prove that both SMC and BSC are robust under external uncertainties. In fact, by using these techniques, both joint trajectories follow the desired trajectory with a high performance. However, SMC is more stable and robust especially via the joint $\mathrm{J} 2$ tracking trajectory.

Figure 4 represents torques variations by SMC and BSC for Joint J1 and Joint J2, respectively.

We admit that both SMC and BSC are efficient and robust techniques. But, the control signal with BSC is smoother than SMC technique.

Figure 5 represents sliding surfaces and the trajectories error tracking of the two joints J1 and J2. Simulation results prove the good performances of the SMC technique. 


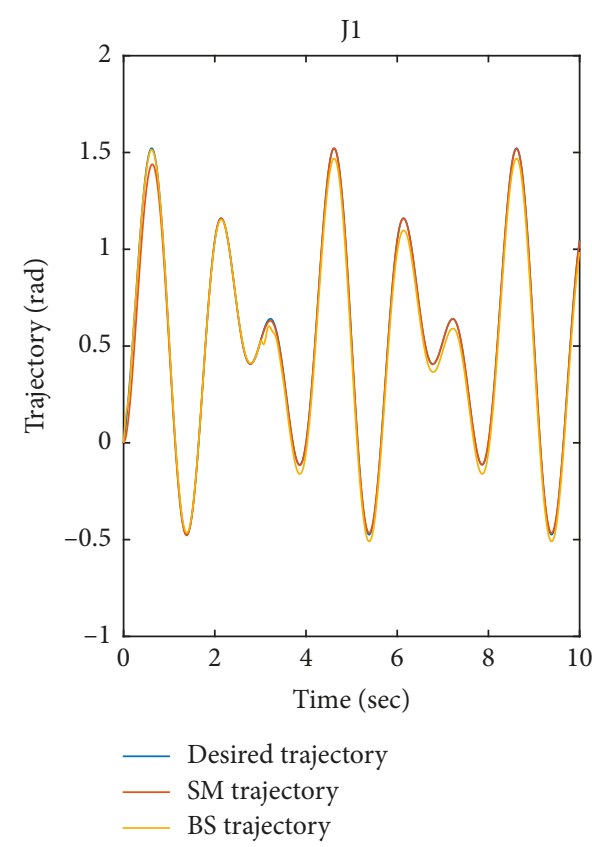

(a)

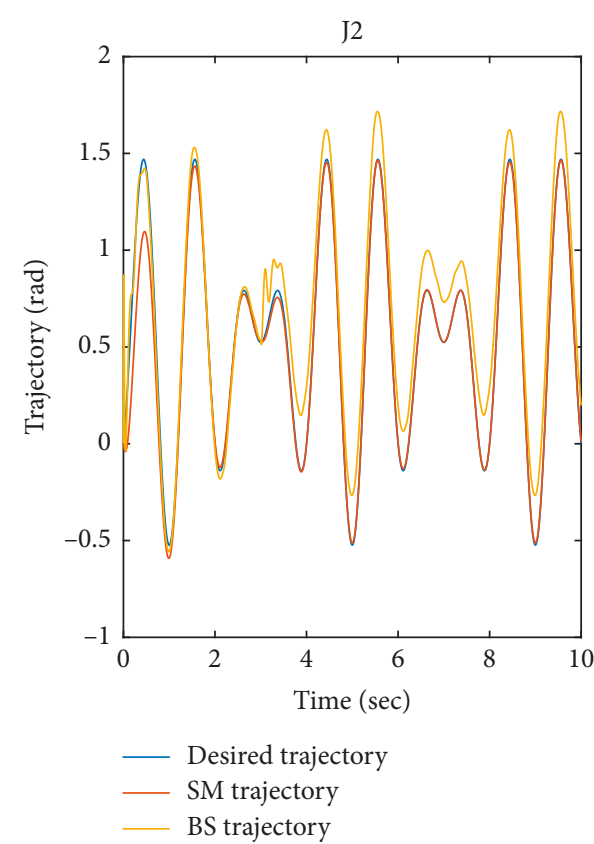

(b)

FIgURE 3: Joints trajectories. (a) J1; (b) J2.

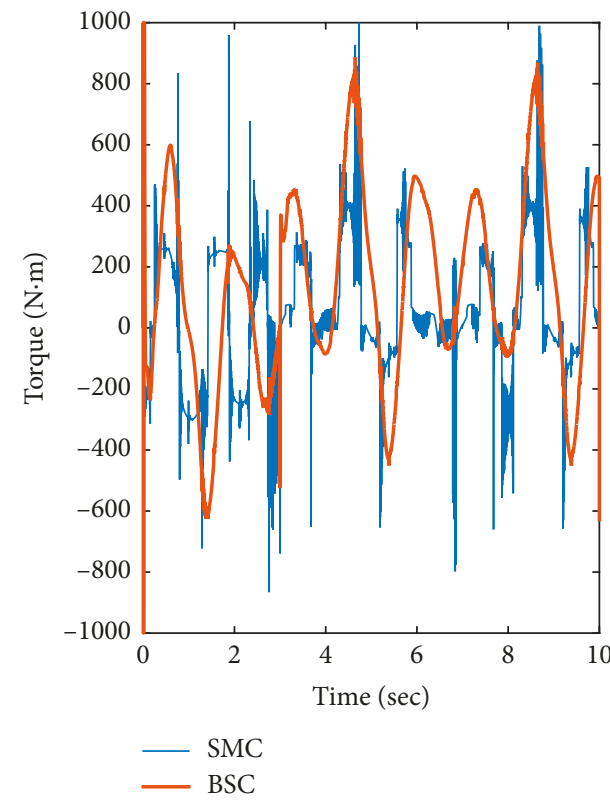

(a)

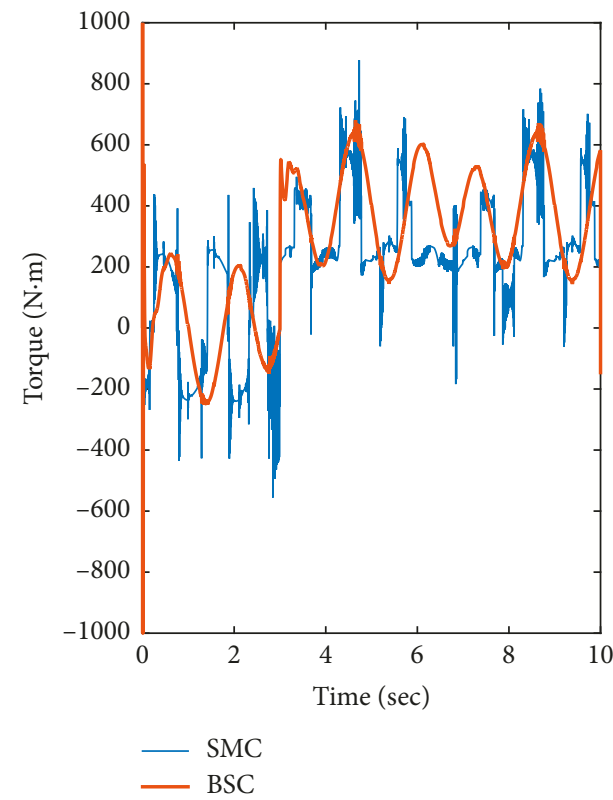

(b)

FIGURE 4: Joints torques.

\subsection{Results with Sinusoidal Perturbation. At $t=3 \mathrm{~s}$}

$$
\begin{aligned}
& d_{1}=300 \cos (1.7 \pi(t+12))+270 \sin (\pi t), \\
& d_{2}=250 \sin (1.35 \pi(t+12))+300 \cos (2 t) .
\end{aligned}
$$

Figure 6 represents the trajectory tracking manipulator of joints $\mathrm{J} 1$ and $\mathrm{J} 2$, respectively, by using SMC and BSC controllers.
The obtained results show the performance of both methods. Yet, BSC is more rapid while SMC is more robust against external perturbations.

Figure 7 represents torque variations by SMC and BSC for Joint J1 and Joint J2, respectively.

The following results are comparable for both controllers. This concludes their effectiveness and robustness. 


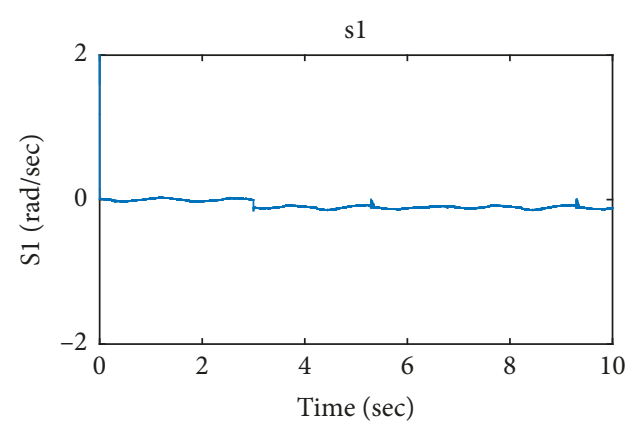

(a)

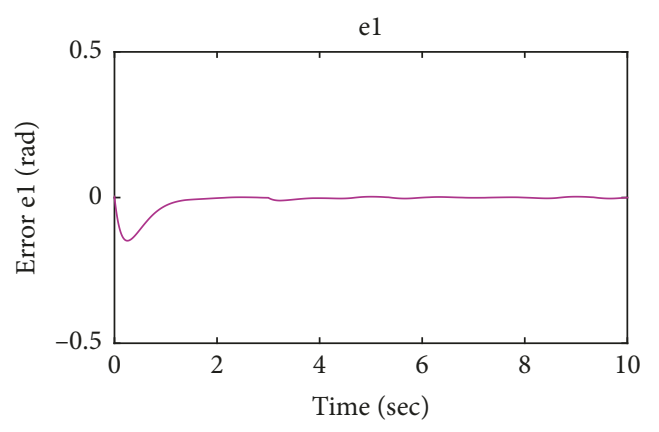

(c)

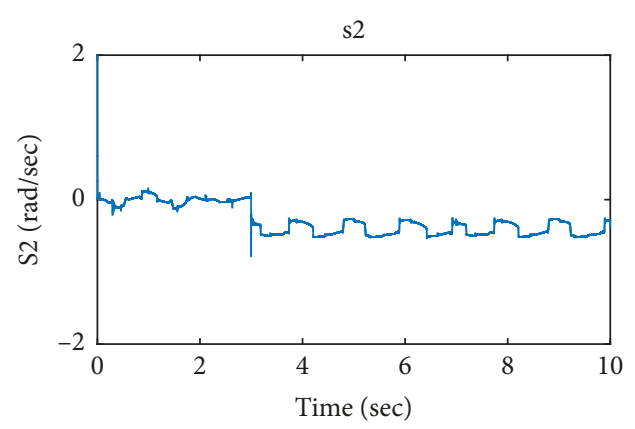

(b)

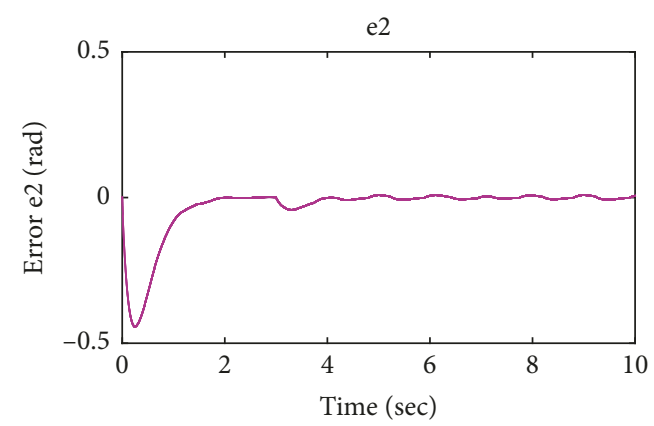

(d)

Figure 5: Sliding surfaces and trajectory errors. (a) s1, (b) s2, (c) e1, and (d) e2.

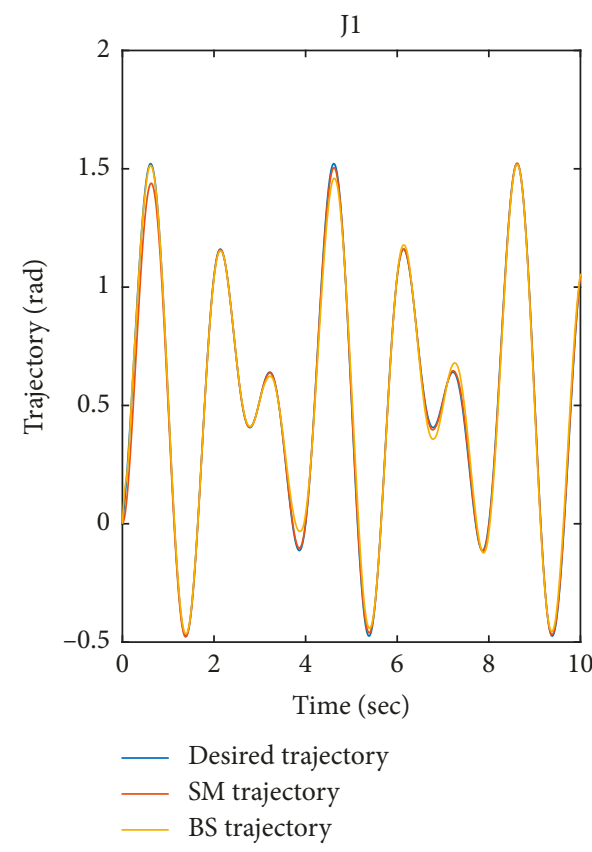

(a)

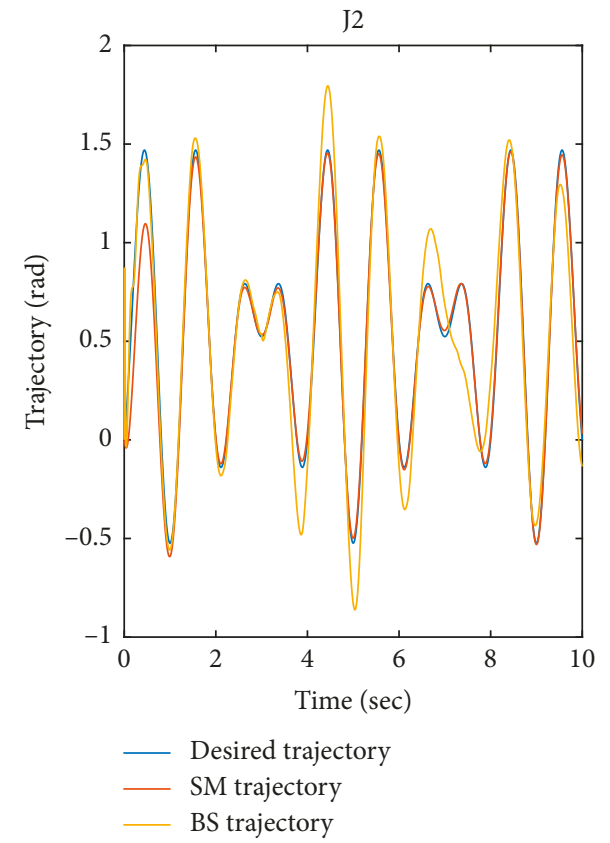

(b)

FIGURE 6: Joints trajectories. (a) J1; (b) J2.

Figure 8 represents sliding surfaces and trajectories error tracking of joints $\mathrm{J} 1$ and $\mathrm{J} 2$. The convergence of sliding surfaces is verified. Good performances of SMC technique are then proved.
5.3. Modified SMC with External and Internal Perturbations. At $t=1.2 \mathrm{~s}$,

$$
\begin{aligned}
& d_{1}=200, \\
& d_{2}=400,
\end{aligned}
$$




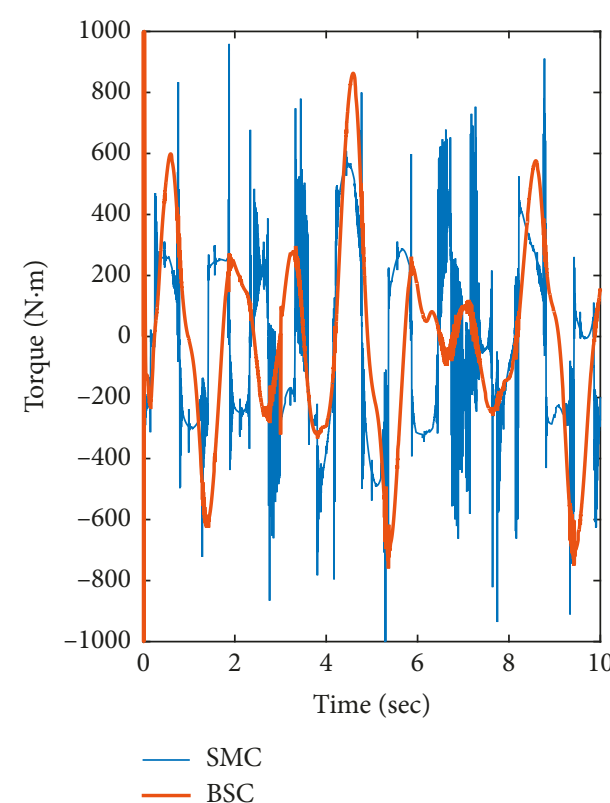

(a)

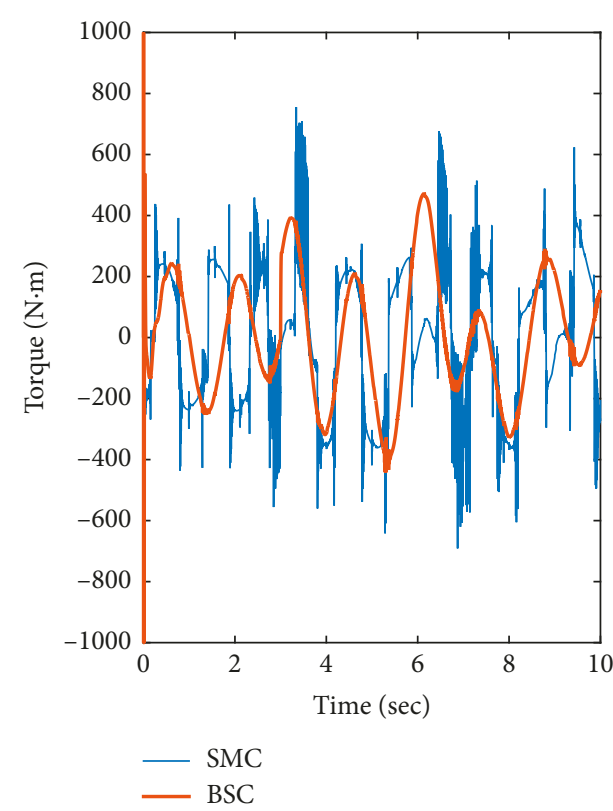

(b)

Figure 7: Joints torques.

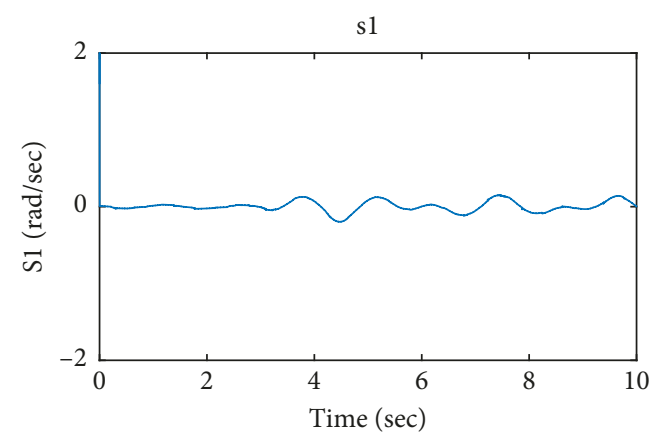

(a)

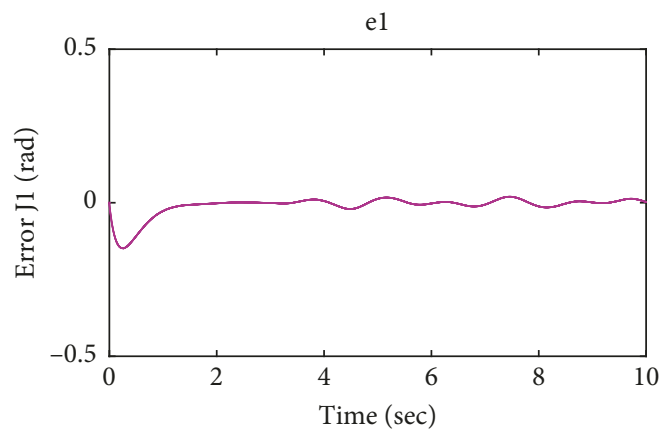

(c)

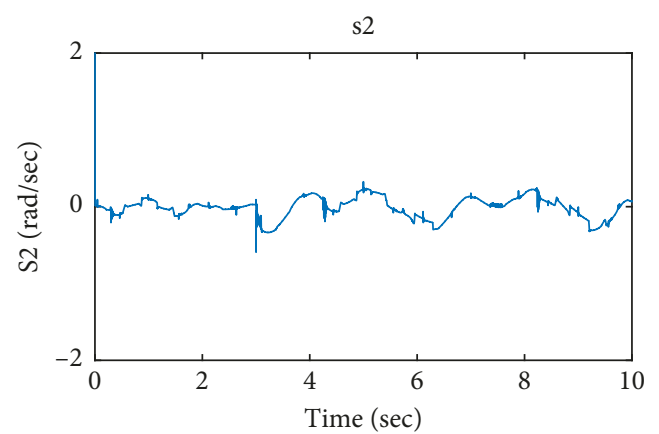

(b)

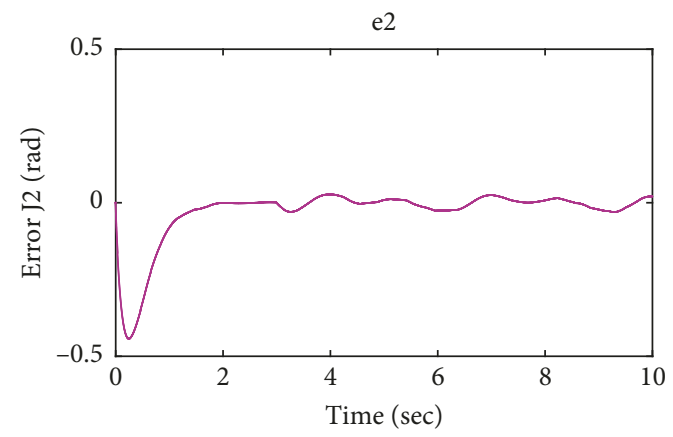

(d)

Figure 8: Sliding surfaces and trajectory errors. (a) s1, (b) s2, (c) e1, and (d) e2.

and at $t=2.6 \mathrm{~s}, m_{\mathrm{e}}=5 \mathrm{~kg}$.

Figure 9 represents the trajectories tracking of the manipulator and torque variations, using SMC technique for joints $\mathrm{J} 1$ and $\mathrm{J} 2$, respectively. In spite of the existence of external and internal uncertainties, the actual trajectory keeps on following the desired one. This method has been successfully performed. Robustness under uncertainties has been deduced.

Figure 10 represents sliding surfaces and trajectories error tracking of joints J1 and J2. Convergence of sliding surfaces has been proved via simulation results.

At $t=1.2 \mathrm{~s}$, 


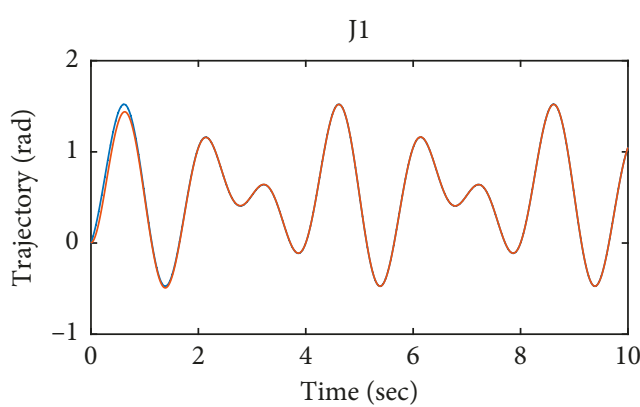

— Desired trajectory

— Actual trajectory

(a)

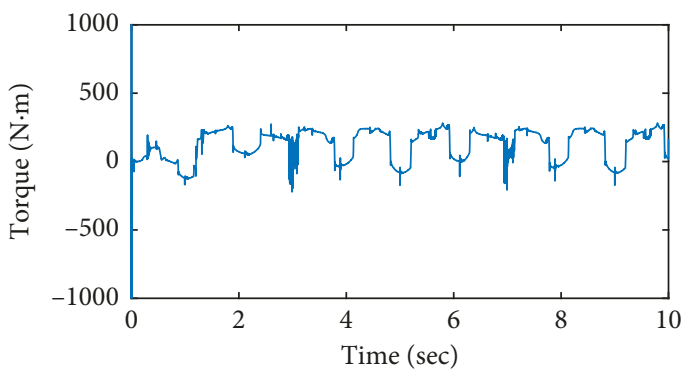

— Desired trajectory

(c)

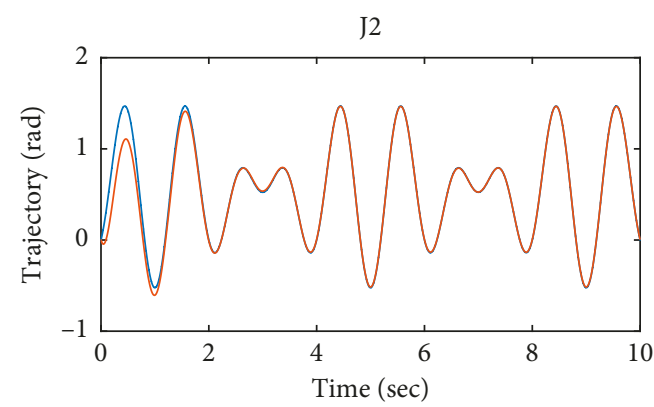

— Desired trajectory

— Actual trajectory

(b)

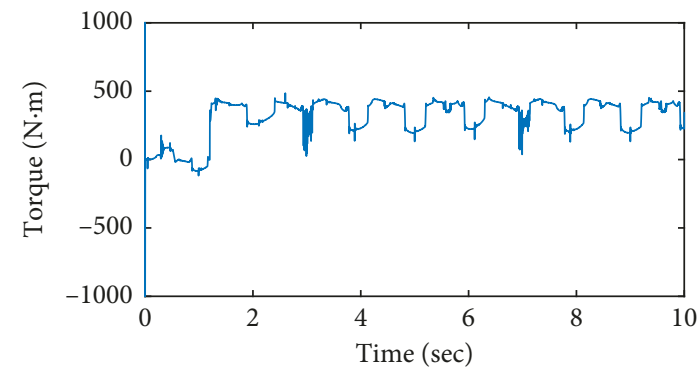

— Desired trajectory

(d)

Figure 9: Joints trajectories and torques.

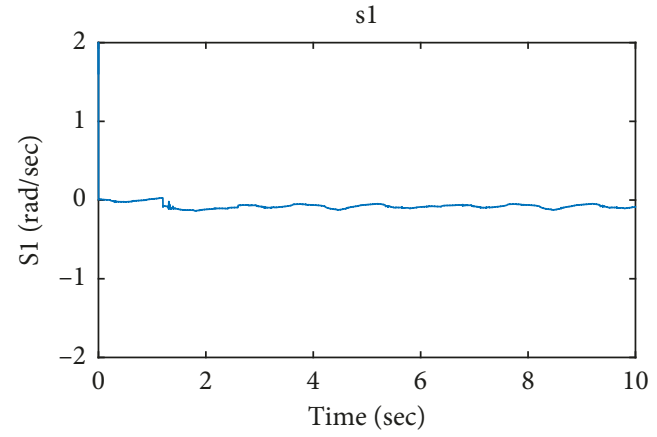

(a)

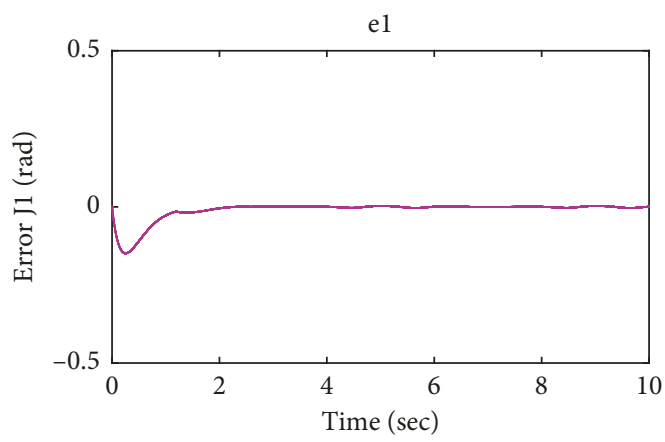

(c)

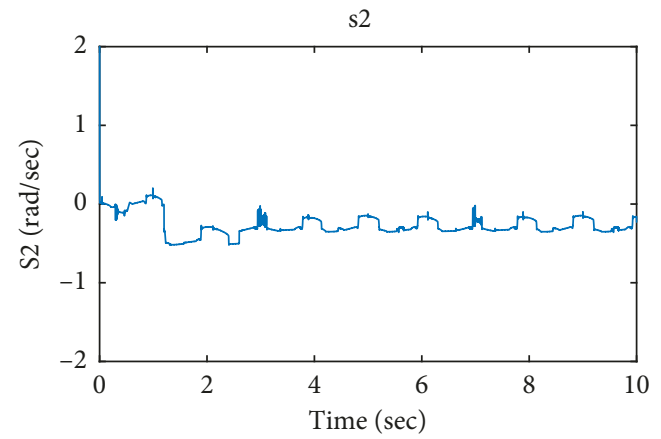

(b)

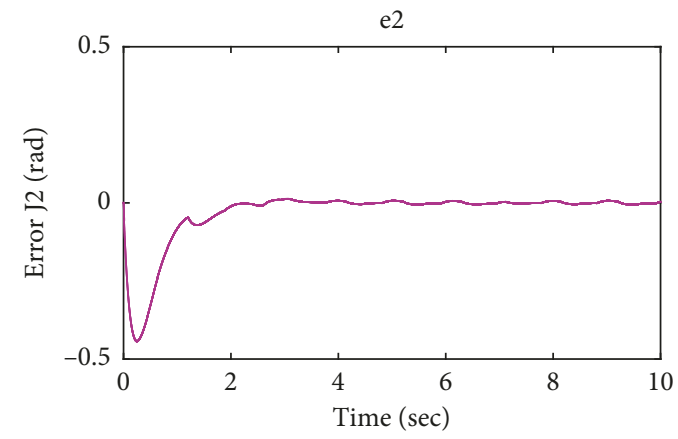

(d)

Figure 10: Sliding surfaces and trajectory errors. (a) s1, (b) s2, (c) e1, and (d) e2. 


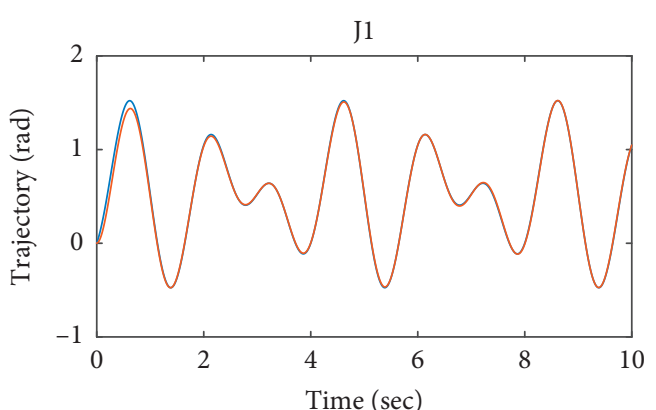

— Desired trajectory

— Actual trajectory

(a)

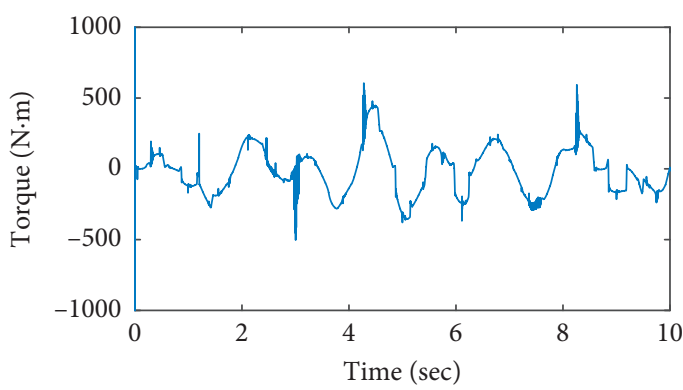

— Desired trajectory

(c)

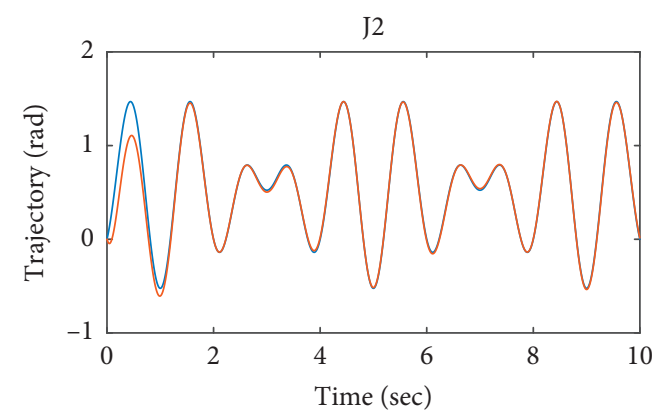

— Desired trajectory

— Actual trajectory

(b)

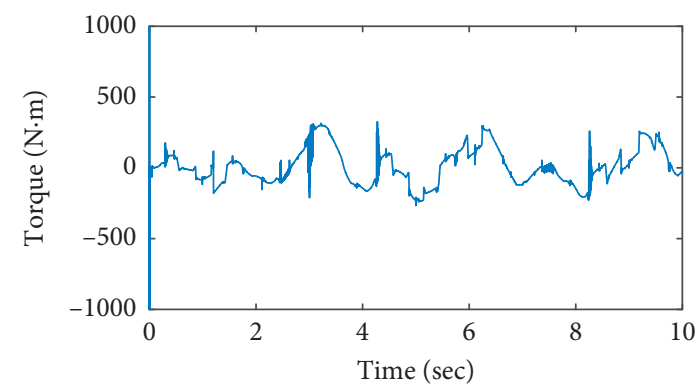

— Desired trajectory

(d)

Figure 11: Joints trajectories and torques.

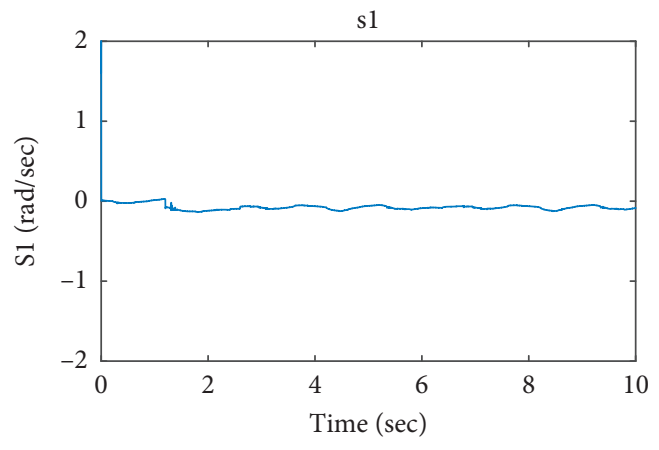

(a)

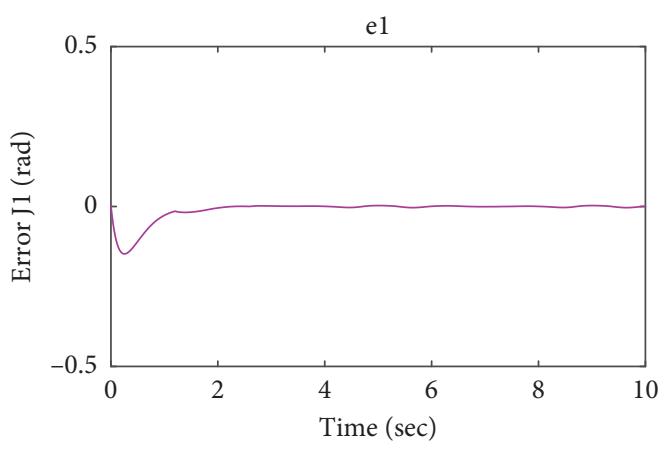

(c)

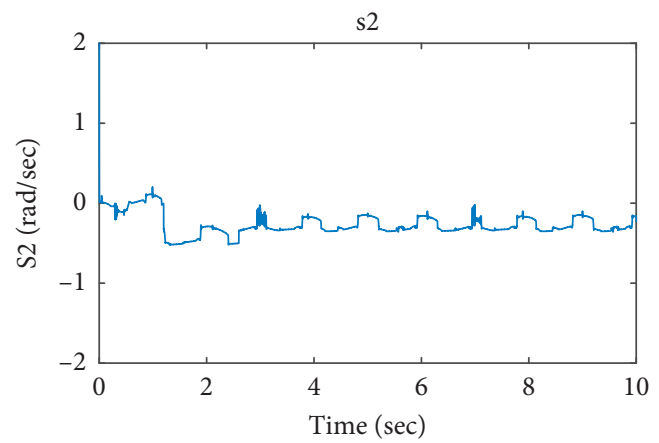

(b)

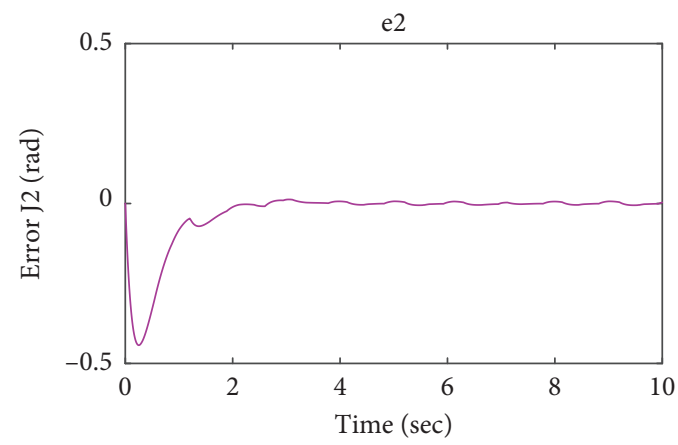

(d)

FIgURE 12: Sliding surfaces and trajectory errors. (a) s1, (b) s2, (c) e1, and (d) e2. 


$$
\begin{aligned}
& d_{1}=300 \cos (1.7 \pi(t+12))+270 \sin (\pi t), \\
& d_{2}=250 \sin (1.35 \pi(t+12))+300 \cos (2 t)
\end{aligned}
$$

and at $t=2.6 \mathrm{~s}, m_{\mathrm{e}}=5 \mathrm{~kg}$.

Figure 11 represents the trajectories tracking of the manipulator and torques variations using SMC for joints J1 and $\mathrm{J} 2$, respectively. Simulation results are performing. In spite of the existence of internal perturbations added to external sinusoidal variations, the system is stable and robust.

Figure 12 represents sliding surfaces and the trajectories error tracking of joints J1 and J2. Convergence and performance of the system controlled by sliding mode have been reached.

\section{Conclusion}

In this work, two robust techniques have been applied to control a two-degree-of-freedom robot. A modified sliding mode control has been developed and a backstepping control has been studied for this uncertain nonlinear system. Simulation results prove the performance and effectiveness of both controllers. Sliding mode control is more robust, taking into account uncertainties, while backstepping is more rapid. Modified SMC has reached the same performance and robustness as adaptive sliding mode control. In order to ameliorate robustness and performance of uncertain nonlinear systems, a combination of both SMC and BSC may be proposed and high-order sliding mode control may also be developed.

\section{Data Availability}

The data used to support the findings of this study are available from the corresponding author upon request.

\section{Disclosure}

This paper is a continuity of the conference paper presented in 2017 at the 18th International Conference on Sciences and Techniques of Automatic Control and Computer Engineering (STA).

\section{Conflicts of Interest}

The authors do not have any conflicts of interest to declare.

\section{Authors' Contributions}

Fatma Massaoudi developed the theoretical studies and wrote the paper. Dorssaf Elleuch and Tarak Damak verified the whole work development and simulation results.

\section{Acknowledgments}

This study was supported by Sciences and Techniques of Automatic Control and Computer Engineering Laboratory (Lab-STA) from Tunisia.

\section{References}

[1] F. Massaoudi, D. Elleuch, and T. Damak, "On the use of differentiator in sliding mode control of uncertain robot manipulator," in Proceedings of the 2017 18th International Conference on Sciences and Techniques of Automatic Control and Computer Engineering (STA), Monastir, Tunisia, December 2017.

[2] Y. Zhang, B. Fidan, and P. A. Ioannou, "Backstepping control of linear time varying systems with known and unknown parameters," IEEE Transactions on Automatic Control, vol. 48, no. 11, pp. 1908-1925, 2003.

[3] H. A. Abbas, M. Belkheiri, and B. Zegnin, "Feedback linearization control for highly uncertain nonlinear systems augmented by single-hidden-layer neural networks," Journal of Engineering Science and Technology Review, vol. 8, no. 2, pp. 215-224, 2015.

[4] M. Zeinali and L. Notash, "Adaptive sliding mode control with uncertainty estimator for robot manipulators," Mechanism and Machine Theory, vol. 45, no. 1, pp. 80-90, 2010.

[5] C.-Y. Chen, T.-H. S. Li, Y.-C. Yeh, and C.-C. Chang, "Design and implementation of an adaptive sliding-mode dynamic controller for wheeled mobile robots," Mechatronics, vol. 19, no. 2, pp. 156-166, 2009.

[6] F. Piltanand and N. B. Sulaiman, "Review of sliding mode of robotic manipulator," World Applied Sciences Journal, vol. 18, no. 12, pp. 1855-1869, 2012.

[7] N. M. B. Ramdhane and T. Damak, "Higher order sliding mode control of uncertain robot manipulators," in Advances and Applications in Sliding Mode Control Systems, vol. 576, pp. 327-352, Springer, New York, NY, USA, 2015.

[8] T. Damak, "Commande par mode glissant d'un robot manipulateur," in Proceedings of the Premier Congrès International Conception et Modélisation des Systèmes Mécaniques CMSM, pp. 1-12, Hammamet, Tunisia, March 2005.

[9] F. J. Bejarano and L. Fridman, "High order sliding mode observer for linear systems with unbounded unknown inputs," International Journal of Control, vol. 83, no. 9, pp. 1920-1929, 2010.

[10] K. C. Veluvolu, Y. C. Soh, and W. Cao, "Robust observer with sliding mode estimation for non linear uncertain systems," IET Control Theory \& Applications, vol. 1, no. 5, pp. 15331540, 2007.

[11] J.-J. E. Slotine, "Sliding controller design for non-linear systems," International Journal of Control, vol. 40, no. 2, pp. 421-434, 1984.

[12] M. Smaoui, X. Brun, and D. Thomaset, "High-order sliding mode for an electropneumatic system: a robust differentiatorcontroller design," International Journal of Robust and Nonlinear Control, vol. 18, no. 4-5, pp. 481-501, 2008.

[13] F. Qiao, Q. Zhu, F. T. Winfield, and C. Melhuish, "Adaptive sliding mode control for MIMO nonlinear systems based on fuzzy logic scheme," International Journal of Automation and Computing, vol. 1, no. 1, pp. 51-62, 2004.

[14] A. J. koshkouei, A. S. I. Zinober, and K. J. Burnham, "Adaptive sliding mode backstepping control of non linear systems with unmatched uncertainty," Asian Journal of Control, vol. 6, no. 4, pp. 447-453, 2008.

[15] A. A. Wang and W. Daobo, "Modeling and backsteppingbased nonlinear control strategy for a 6 DOF quadrotor helicopter," Chinese Journal of Aeronautics, vol. 21, no. 3, pp. 261-268, 2008.

[16] A. Guezmil, H. Berriri, A. Sakly, and M. F. Mimouni, "Backstepping Control for Induction Machine With High 
Order Sliding Mode Observer and Unknown Inputs Observer: A Comparative Study," in Proceedings of the 2014 International Conference on Electrical Sciences and Technologies in Maghreb (CISTEM), IEEE, Tunis, Tunisia, November 2014.

[17] Y. Yang, G. Feng, and J. Ren, "A combined backstepping and small-gain approach to robust adaptive fuzzy control for strict-feedback nonlinear systems," IEEE Transactions on Systems, Man, and Cybernetics_Part A: Systems and Humans, vol. 34, no. 3, pp. 406-420, 2004.

[18] M. Ariffanan, M. Basri, K. A. Danapalasingam, and A. R. Husain, "Design and optimazation of backstepping controller for an underactuated autonomous quadrator unmanned aerial vehicle," Transactions of Famena, vol. 38, no. 3 , pp. 27-44, 2014.

[19] T. Madani and A. Benallegue, "BacksteppingControl for a quadrotor helicopter," in Proceedings of the 2006 IEEE/RSJ International Conference on Intelligent Robots and Systems, pp. 3255-3260, Beijing, China, October 2006.

[20] G. Regula and B. Lantos, "Backstepping based control design with state estimation and path tracking to an indoor quadrotor helicopter," Periodica Polytechnica Electrical Engineering, vol. 53, no. 3-4, pp. 151-161, 2009.

[21] A. J. Koshkouei and A. S. I. Zinober, "Adaptive sliding backstepping control of nonlinear semi-strict feedback form systems," in Proceedings of the 7th IEEE Mediterranean Control Conference, pp. 2376-2383, Haifa, Israel, October 1999. 


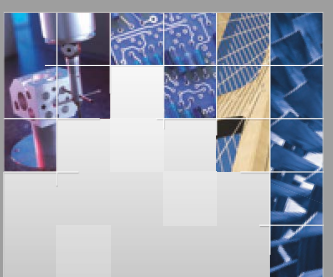

\section{Enfincering}
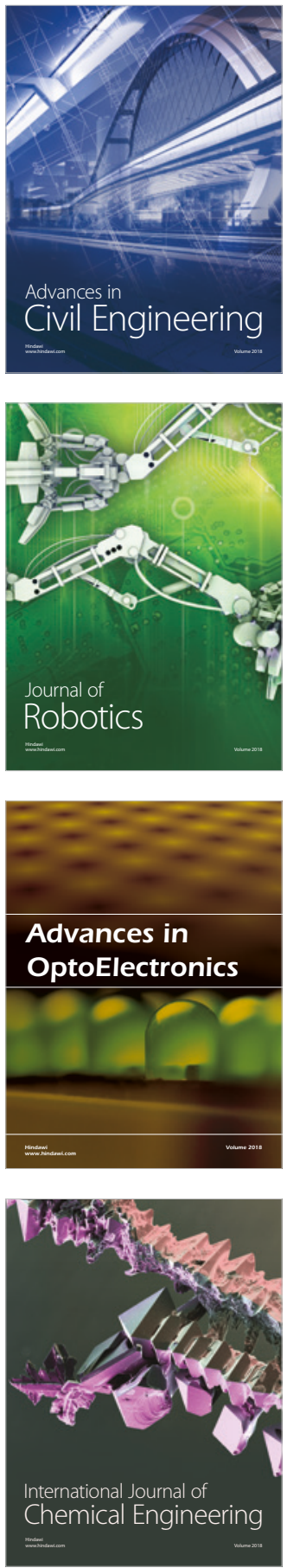

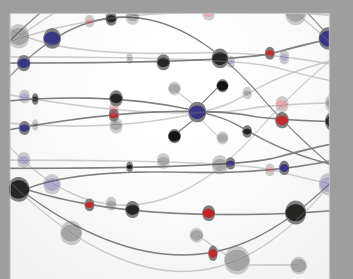

\section{Rotating \\ Machinery}

The Scientific World Journal

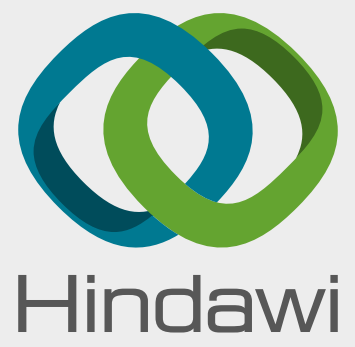

Submit your manuscripts at

www.hindawi.com
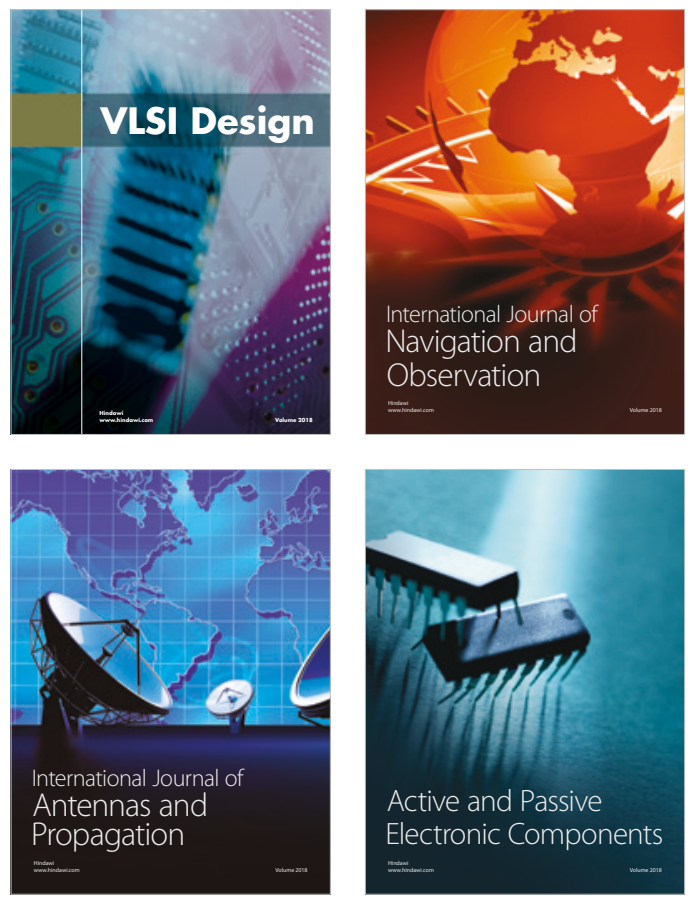
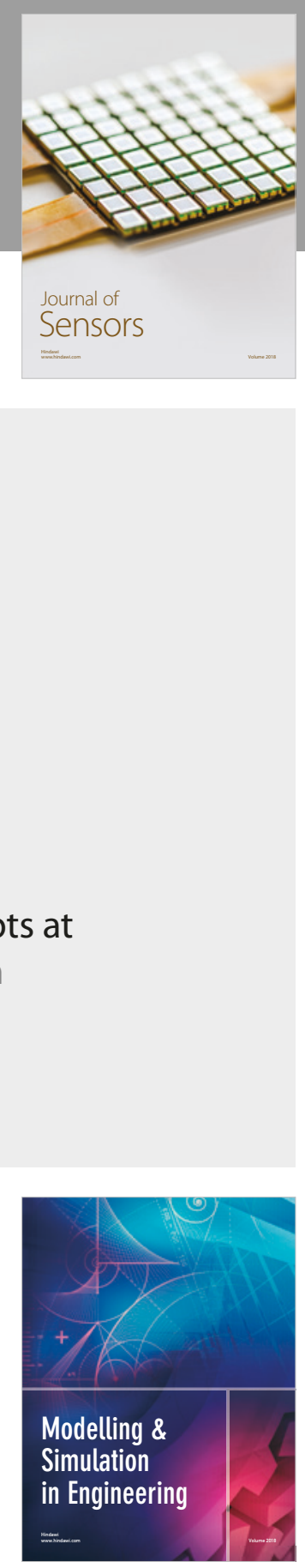

\section{Advances \\ Multimedia}
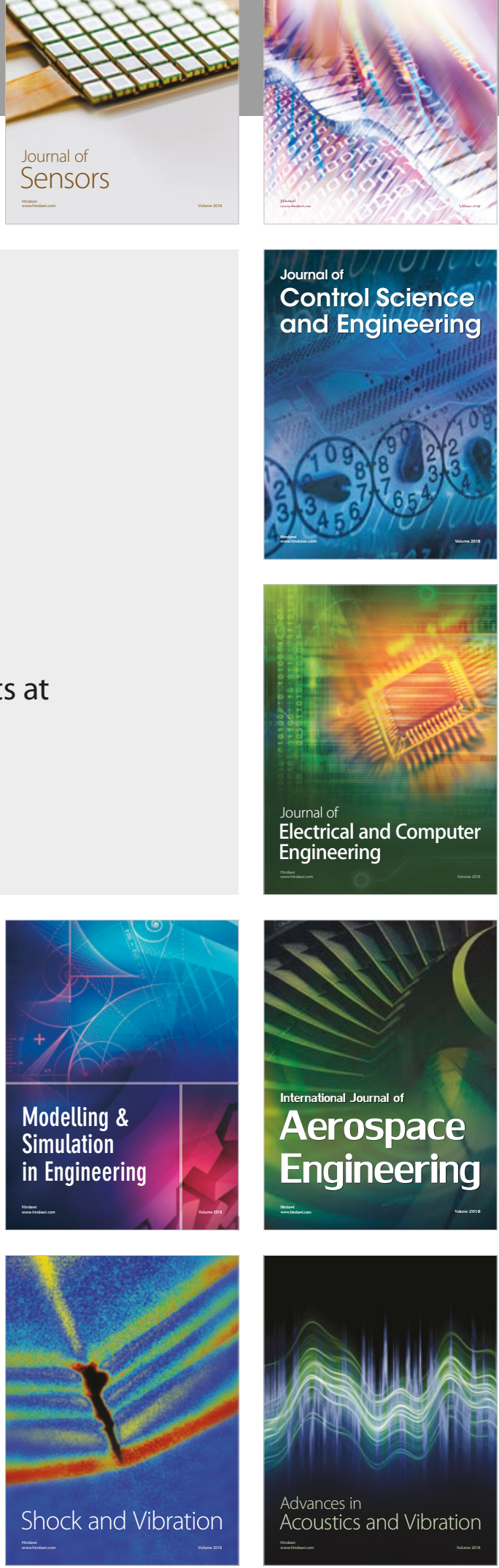